\title{
Cities, Slums, and Child Nutrition in Bangladesh
}

\author{
Dhushyanth Raju \\ Kyoung Yang Kim \\ Quynh Thu Nguyen \\ Ramesh Govindaraj
}

This study uses novel household survey data that are representative of Bangladesh's large cities, and of slum and nonslum areas within the cities, to investigate the effects of demographic and socioeconomic factors on child nutrition status in 2013. The study also decomposes the difference in mean child nutrition status between slum and nonslum areas in 2013, and the increase in mean child nutrition status in slum and nonslum areas from 2006 to 2013. Mother's education attainment and household wealth largely explain the cross-sectional difference and intertemporal change in mean child nutrition status. Although positive in some cases, the effects of maternal and child health services, and potential health-protective household amenities, on child nutrition status differ by the type of health facility, household amenity, and urban area (slum or nonslum). Focusing on nutrition-sensitive programs for slum residents and the urban poor is consistent with the results.

JEL codes: I12; I14; I15; O15

Key words: $\quad$ South Asia; Bangladesh; urban; slums; undernutrition; height-forage z scores; children 


\section{INTRODUCTION}

Urbanization is one of the most important demographic currents historically. It offers a major opportunity for countries to broaden and boost gains in the socioeconomic status of urban residents. On the other hand, rapid urbanization poses significant development risks, arising from inadequate or low-quality physical and economic infrastructure and a failure to provide basic services for growing urban populations. The tension between the potential opportunities and perils of urbanization is arguably stronger for developing countries, for at least two reasons. First, these countries are expected to experience large expansions in their already substantial urban populations in the coming decades. The total urban population in the least-developed countries was estimated to be 2.9 billion in 2014, and the figure is projected to reach 5.2 billion by 2050 (UN 2015a). Second, governments in developing countries generally have had a poor record in designing, financing, and implementing policies, rules and regulations, and in providing services in both urban and rural areas, resulting in conditions and outcomes that may be socially inefficient and inequitable (UN-Habitat, 2016).

The global imperative to leverage the potential socioeconomic benefits of urbanization, and mitigate potential risks, is reflected in for example the 2030 Agenda for Sustainable Development (Goal 11) and the New Urban Agenda adopted by the UN in 2015 and 2016, respectively (UN, 2015a; UN, 2017). Protecting and promoting the health of urban residentsincluding slum and poor residents who face a greater risk to their health and nutrition from higher exposure to adverse environmental factors-is a key element in the UN agenda on urbanization.

Notwithstanding, urban health and nutrition in developing countries is an understudied area. In the case of Bangladesh, the setting for this study, most of the available evidence comes 
from qualitative studies and empirical research based on small-scale purposive samples or largescale samples that are representative for urban areas as a whole (for example, see Choudhury et al., 2012; Srinivasan, Zanello, \& Shankar, 2013). These studies point to substantial inequities in health and nutrition service delivery and outcomes within complex, dynamic, and dense urban environments. The amount and nature of rigorous empirical research on urban health and nutrition has been constrained by the absence of large-scale data in developing countries that are representative across and within urban areas in a country, and are extensive in terms of capturing potential determinants.

In this study, we empirically investigate patterns, trends, and determinants of the nutrition status of children under age five in the major cities of Bangladesh, with a focus on differences between slum and nonslum children, using data from a large-scale household survey that is relatively unique for a developing country (Ezeh et al., 2017). In 2006, the National Institute of Population Research and Training (NIPORT) and others conducted the Bangladesh Urban Health Survey (BUHS), providing, for the first time, extensive data on adult and child health and nutrition outcomes, and a wide range of potentially relevant factors, that are representative for slum and nonslum areas in city corporations (the country's major cities), and for district municipalities and large towns. In 2013, the survey was repeated on a new cross-section which is representative for the same domains. The two rounds of the BUHS serve as the source of data for this study.

The health and nutrition status of slum residents is of interest for at least three reasons. First, theory and evidence suggest that the study of slum health and nutrition should be treated as distinct from the study of urban health, or the study of poverty and health (Ezeh et al., 2017). One argument for the separate treatment is that the physical and social environments of slum 
settlements may act to amplify health risks for residents, and produce negative health externalities. The exposure to concentrated health risks in slum settlements may be particularly harmful to young children, given that they are more immunologically susceptible than older children and adults. Second, the literature on slum health and nutrition is scant (see Ezeh et al., 2017 for a recent review). Third, research is needed on the health and nutrition risks and effects of residing in a slum settlement to guide the design and implementation of policies and interventions related to slum development in general and slum health in particular (Lilford et al., 2017).

We measure the nutrition status of children under age five by height-for-age z-scores (HAZ). Height is widely regarded as the most relevant measure of overall child nutrition, and child stunting (a height-for-age z-score that is more than two standard deviations [SD] below the international reference median) is viewed as the key indicator for tracking progress in addressing child undernutrition. Stunting reflects the cumulative effects of poor diet and recurrent infection. International evidence suggests that stunting has negative effects on important short- and longterm outcomes (Black et al., 2008; Cesar et al., 2008; Currie \& Vogl, 2013; Black et al., 2013). The stunting rate stood at 36\% in Bangladesh, and at 31\% for urban areas, based on the 2014 Bangladesh Demographic and Health Survey (DHS) (NIPORT et al., 2016). The country's national stunting rate ranks 107 out of 132 countries (IFPRI, 2016).

We begin by investigating the effects of child, maternal, household, and neighborhoodarea factors on HAZ for slum and nonslum children in reduced-form estimations, using the 2013 BUHS. We estimate regressions with administrative-division fixed effects, as well as regressions with neighborhood-area fixed effects, thus respectively accounting for unobserved heterogeneity at the division and neighborhood-area levels. Ahsan et al. (2017) perform a similar analysis for 
Bangladesh, examining the effects of various factors on stunting and underweight status for slum and nonslum children also using the 2013 BUHS. They find that the child's age, mother's education attainment, and household wealth are significant factors for slum and nonslum children, and that mother's membership in an NGO and the child's birth order are additional significant factors for nonslum children.

We then extend our analysis in four potentially policy-relevant directions, which represent the main contributions of the study. The first three directions use the 2013 BUHS, whereas the fourth direction uses both the 2006 and 2013 BUHS. First, we examine the effects of the local availability of maternal and child health $(\mathrm{MCH})$ services, and of the use of these services. Second, we examine the effects of access to, or use of, potential health-protective household amenities related to cooking fuel, dwelling floor, drinking water, sanitation, and hygiene. We perform these two analyses for all city-corporation children, as well as separately for slum and nonslum children. Third, we examine the extent and nature of the contributions of various factors to the slum-nonslum difference in mean HAZ, based on an extension of the Oaxaca-Blinder counterfactual decomposition method. In 2013, mean HAZ was 0.58 SD lower for slum than nonslum children. Fourth, we examine the extent and nature of the contribution of various factors to the change in mean HAZ for slum and nonslum children in the relevant city corporations, based on the same decomposition method. Between 2006 and 2013, mean HAZ increased by 0.23 SD for slum children and by 0.20 SD for nonslum children.

\section{BACKGROUND}

\section{Urbanization}


Classified as a lower middle-income country, Bangladesh is the eighth most populous country in the world, with an estimated population of 159 million in 2014 (World Bank, 2016). According to the 2011 Bangladesh population and housing census (GOB, 2014), 23\% of the country's population is urban.

Urban centers in Bangladesh are essentially organized into three levels: city corporations, municipal cities and towns, and upazilla headquarters. According to the 2011 census (GOB, 2014), Bangladesh had 506 urban centers: six city corporations (Barisal, Chittagong, Dhaka, Khulna, Rajshahi, and Sylhet), 311 municipal cities and towns, and 189 upazilla headquarters. The six city corporations accounted for 34\% of the country's total urban population in 2011.

Since 2011, the number of urban centers has grown, and some urban centers have moved up in level. The number of city corporations has grown from six to 11 . Based on published census statistics (GOB, 2014), we estimate that the 11 city corporations that exist today accounted for $41 \%$ of the country's total urban population in 2011.

\section{Slum settlements}

Slum settlements are an important phenomenon in urban Bangladesh. According to a 2014 government census of slum settlements, the country had approximately 14,000 of them in all urban areas, with a total slum population of 2.2 million (GOB, 2015). Sixty-five percent of slum settlements were located in city corporations, $24 \%$ in municipal cities and towns, and $11 \%$ in upazilla headquarters or other urban areas. Slum settlements varied substantially in size: on the low end, $27 \%$ of slum settlements had fewer than 10 households, whereas on the high end, $7 \%$ of slum settlements had at least 100 households. 
Based on a 2005 independent census and mapping of slum settlements in the six city corporations that existed at the time, Angeles et al., 2009 document several interesting patterns in the characteristics of slum settlements. We note four patterns. First, there were large differences in the population sizes, and housing and public environmental conditions, of slum settlements within and across cities. Large slum settlements were a feature of the larger cities. Second, waste management (garbage disposal and collection, and sanitation) tended to be poorer than other public environmental facilities in slum settlements. Third, the vast majority of slum settlements were situated on private lands, and slum residents tended to have secure tenure. In addition, housing construction tended to be of better quality in slum settlements on private lands, which we presume is a result of residents having secure tenure. Fourth, a large share of slum residents were rural migrants, mostly from rural communities near to the city corporation.

The 2006 and 2013 BUHS reports (NIPORT et al., 2008; NIPORT et al., 2015) and case studies using other data find that slum residents generally have poor mean socioeconomic circumstances and outcomes (for example, see Islam, Farukuzzaman, \& Islam, 2014; Nahar \& Rahman, 2013; Hossain, Moniruzzaman, \& Islam, 2010). The findings are consistent with evidence for slum residents globally (for example, see UN-Habitat, 2016). These results, however, directly follow from the definition of a slum settlement.

\section{Urban primary health services}

While nutrition sensitive in nature, primary health services in Bangladesh, in particular reproductive, maternal, newborn, and child health (RMNCH) services serve as a main delivery 
mode for nutrition-specific interventions. ${ }^{1}$ Given this, we conduct an extended review of the empirical and qualitative research on the supply and demand for, and quality of, such services in the country's urban areas.

Supply: Urban governments, which are mainly responsible for public primary health services in their areas, have contracted out the operation of a majority of public primary health facilities to NGOs. Nongovernmental organizations also operate their own facilities. Urban governments and NGOs deploy community health workers (CHWs) to engage in health promotion and preventive care outreach in poor neighborhoods. ${ }^{2}$ The government and international donor agencies have supported NGO provision of RMNCH services through several initiatives, such as the Bangladesh Smiling Sun Franchise Program (BSSFP), started in 2007, and the Bangladesh Urban Primary Health Care Project (BUPHCP), started in 1998. The NGO BRAC also provides RMNCH services through its Manoshi initiative, started in 2007.

Private providers also offer RMNCH services. They are fee-based and operate for profit, and include hospitals, clinics, nursing homes, diagnostic centers, and pharmacies, as well as private practices by medical doctors and nonformal or traditional healthcare practitioners. Private health facilities tend to have wider service coverage and longer, more convenient service hours than public or NGO health facilities. A large share of private providers charge low fees, making

\footnotetext{
${ }^{1}$ Nutrition-specific programs are those that target the immediate causes of undernutrition as identified in UNICEF's (1998) conceptual framework, namely inadequate nutrient intake and poor health. Nutrition-sensitive programs are those that target the underlying and basic causes of undernutrition.

${ }^{2}$ Community health workers in villages have been credited for the notable declines in fertility and maternal and child mortality, and gains in child vaccination rates and uptake of oral rehydration therapy, in Bangladesh (El Arifeen et al., 2013).
} 
them affordable to poor households (Adams, Islam, \& Ahmed, 2015; Afsana \& Wahid, 2013). However, private providers tend to operate without required licenses, and their staff often lack required academic and professional qualifications (ICDDRB, 2015). Compared to staff at public or NGO health facilities, private providers are less likely to be familiar with government guidelines for healthcare practice management (ICDDRB, 2015).

A census of health service providers located in, or near, a sample of slum settlements in Dhaka city found that more than $80 \%$ were private, $12 \%$ were public (but contracted out to NGOs to operate), and 6\% were NGO. Thirty-eight percent of private providers were pharmacies, while 35\% were nonformal or traditional healthcare practitioners. (Pharmacies not only sell drugs but also provide diagnostic and treatment advice.) More than $60 \%$ of private healthcare staff were unqualified, compared to $2 \%$ of public healthcare staff. Fifty percent of NGO healthcare staff were community health workers (Adams, Islam, \& Ahmed, 2015).

A few studies have examined the effects of RMNCH service provision on use, interpreting the results as causal. While the effects are not well identified, the studies tend to find that provision promotes use. For example, comparing slum settlements in Dhaka metropolitan area covered by the Manoshi program to those in the outskirts of Dhaka city corporation, and before and four years after the program was initiated, Alam et al. (2011) find that the program increased both the use of maternal and child health services and favorable newborn practices, and, to a lesser extent, mother's knowledge about maternity care and newborn health problems. Comparing urban areas covered by the Bangladesh Smiling Sun Franchise Program to adjacent areas, and one and four years after the program was initiated, Lance, Angeles, \& Kamal (2012) find that the program did not have positive effects on the rates of use of modern contraceptives, use of antenatal care services, or vaccination. The authors indicate that the results are due to a 
growing intensity of other government and NGO maternal and child health service activity in the comparison areas.

Demand: Kamal et al. (2016) find a large increase in the use of maternal and child health services over the first decade of the 2000s in both urban and rural areas in Bangladesh, and that the difference by household economic status in the use of such services has narrowed, particularly in urban areas. They also find that the use of private maternal and child health services dominates, although the use of such services is lower among poorer households.

Slum residents in Dhaka city report that they prefer seeking health care from pharmacies and nonformal or traditional healthcare practitioners, and prefer home deliveries by traditional birth attendants (Adams, Islam, \& Ahmed, 2015). These findings are consistent with other evidence for urban slum and poor households in Bangladesh (for example, see Nahar \& Rahman, 2010 for Chittagong city). The findings are also consistent with evidence for many other developing countries that the poor tend to obtain care from informal private health practitioners, who often lack required academic and professional qualifications or are unlicensed to practice (Sudhinaraset et al., 2013).

Gazi et al. (2015) examine the reasons reported by nonusers of maternal and child health services provided by NGO health facilities in Sylhet city under the Bangladesh Urban Primary Health Care Project and the Bangladesh Smiling Sun Franchise Program. They find that the main reasons include the lack of awareness of services, the limited range of offered services, and the availability of free services at public health facilities. Using 2006 BUHS data, Islam \& Gagnon (2016) find that women who moved to the city are less likely to use maternal and child health services. Adams, Nababan, \& Hanifi (2015) find that mothers who have community health 
workers as part of their social networks are more likely to use maternal and child health services in selected slum settlements under the Manoshi program in Dhaka city.

Distance may not be an important determinant of household demand for RMNCH services, as suggested by responses from users and nonusers of such services (Gazi et al., 2015). Using 2006 BUHS data, Heller (2013) finds that distance of an area to the nearest primary health facility and the density of primary health facilities in an area do not appear to be associated with the use of antenatal or postnatal care services, whether or not the author accounts for the potential endogeneity of where the household resides.

Quality: The quality of care may influence whether households use maternal and child health services, and which provider type they choose. Rigorous, representative evidence is lacking for urban Bangladesh on provider quality of care (measured either directly or indirectly), and on its determinants. Among the available evidence, Gazi et al. (2015) find that the main reported reasons for user satisfaction with BUPHCP- and BSSFP-supported NGO primary health facilities in Sylhet city were staff professionalism and courtesy, and low-cost or free services. Banu \& Nasreen (2011) find that the performance of Manoshi delivery facilities in some slum settlements in Dhaka varied markedly across facilities; that the retention and effort of community health workers were key factors associated with facility performance; and that facility hygiene, free services, staff courtesy, and lack of space at home were key factors associated with use. Examining the causes of neonatal and maternal deaths in selected slum settlements in Dhaka under the Manoshi program, Khatun et al. (2012) find performance issues existed with community health workers in terms of the coverage and timing of household visits, and the detection and management of, and referral for, risks. 


\section{DATA}

The 2006 and 2013 BUHS were designed to provide data that are representative of three overall domains: (1) slum neighborhoods in city corporations, (2) nonslum neighborhoods in city corporations, and (3) municipal cities and towns. The 2006 round covered the six city corporations existing at that time, and the 2013 round covered 10 of the 11 city corporations existing in that year.

The sample frame for the survey was a complete list of mahallas (which we refer to as neighborhoods) in the city corporations and sampled municipal cities and towns. A mahalla is an Islamic parish, and an optional, non-elective administrative unit below the ward in cities and towns in Bangladesh. Focusing on city corporations, neighborhoods were randomly selected in the first stage of sampling. In each sampled neighborhood, all slum and nonslum areas were mapped through visits. An area was defined to be a slum settlement if it had at least 10 households and met four of the following five conditions: poor housing conditions, insecure housing tenure, high population density, poor sanitation and inadequate water access, and at least $75 \%$ of the households appeared to be poor. These conditions are consistent with UN-Habitat guidelines for defining slums (UN-Habitat, 2003).

The second stage of sampling differed slightly between the 2006 and 2013 rounds, but essentially, slum and nonslum areas of sampled neighborhoods, the primary sampling units (PSUs), were randomly drawn, stratified by slum status. See NIPORT et al. (2008) and NIPORT et al. (2015) for sample design details. We refer to the PSU as "neighborhood area".

We use data from the neighborhood-area, household, and female questionnaires. The neighborhood area questionnaire was administered to knowledgeable leaders and key informants in the neighborhood area. The household questionnaire was usually answered by the female 
spouse of the household head. The female questionnaire was administered to women aged 18-59 (and those ever-married aged 10-17) in 2006, and it was administered to ever-married women aged 15-49 in 2013. The female questionnaire included a module for children under age five, and an additional module for the youngest child born in the three years before the survey, with information provided by the child's mother or guardian. Survey response rates ranged from $93 \%$ to $97 \%$ depending on the survey round, questionnaire type (household, female) and citycorporation subdomain (slum, nonslum).

The full sample for our analysis is 2,264 children under age five in 1,956 households in 254 neighborhood areas (slum: 128; nonslum: 126) in 2006, and it is 7,619 children under age five in 6,848 households in 1,278 neighborhood areas (slum: 449; nonslum: 829) in 2013.

\section{EMPIRICAL STRATEGY}

\section{Multiple regression}

To examine the factors associated with HAZ in 2013, we estimate various multiple regression specifications. The base regression relationship is modeled linearly as

$$
Y_{\text {imha }}=\alpha+X_{\text {imha }} \beta_{I}+X_{\text {mha }} \beta_{M}+X_{\text {ha }} \beta_{H}+X_{a} \beta_{A}+v+\varepsilon_{\text {imha }} \text {, }
$$

where $Y_{\text {imha }}$ denotes the height-for-age z-score for child $i$ from mother $m$ in household $h$ in neighborhood area $a$; $X_{\text {imha }}$ is a vector of child factors; $X_{\text {mha }}$, a vector of maternal factors; $X_{\text {ha }}$, a vector of household factors; $X_{n}$, a vector of neighborhood-area factors; $v$, administrativedivision fixed effects; and $\varepsilon_{i h n}$, the error term. We are interested in the parameter vectors $\beta_{I}$, $\beta_{M}, \beta_{H}$, and $\beta_{A}$. The regressions are estimated based on ordinary least squares. 
We also estimate regressions with neighborhood-area fixed effects, thus accounting for unobserved heterogeneity at the level of the neighborhood area or higher. In all regressions, standard errors are estimated correcting for heteroskedasticity of arbitrary form and clustering at the neighborhood-area level. All regression specifications are estimated for three neighborhoodarea samples: all areas (referred to as pooled), slum areas, and nonslum areas.

\section{Aggregate decomposition}

To examine the extent and nature of the contributions of regression factors to the difference in mean HAZ between slum and nonslum children in 2013, or the changes in mean HAZ between 2006 and 2013 for slum and nonslum children in the relevant city corporations, we apply the extension proposed by Daymont \& Andrisani (1984) to the classical Oaxaca-Blinder counterfactual regression-based decomposition method (Oaxaca, 1973; Blinder, 1973). The Oaxaca-Blinder decomposition method and its extensions have been applied in the healtheconomics literature to investigate differences in mean health outcomes or health service utilization among social, economic, and spatial groups, and between time periods (for example, see Wagstaff, van Doorslaer, \& Watanabe, 2003; Haddad et al., 2012; Kumar \& Singh, 2013). The method has also been applied to nutrition in Bangladesh, for example, to investigate the rural-urban difference in mean HAZ (Srinivasan, Zanello, \& Shankar, 2013) and the intertemporal change in mean HAZ in selected rural areas (Nguyen et al., 2017).

Adapting the notation by Fortin, Lemieux, \& Firpo (2011), and taking the case of decomposing the slum-nonslum difference in mean HAZ in 2013, let $S$ denote a slum neighborhood area, and NS, a nonslum neighborhood area. The linear regression relationship for HAZ is given by 


$$
Y_{g}=X \beta_{g}+\varepsilon_{g}
$$

where $E\left(\varepsilon_{g} \mid X\right)=0$ group $g=(S, N S)$. Let $D_{S}=1$ be an indicator of residing in a slum neighborhood area; zero otherwise. The slum-nonslum difference in mean HAZ, $\Delta^{\mu}$, can be decomposed as follows:

$$
\begin{aligned}
\Delta^{\mu} & =E\left[Y_{S} \mid D_{S}=1\right]-E\left[Y_{N S} \mid D_{S}=0\right] \\
& =\left\{E\left[X \mid D_{S}=1\right]\left(\beta_{S}-\beta_{N S}\right)\right\} \\
& +\left\{\left(E\left[X \mid D_{S}=1\right]-E\left[X \mid D_{S}=0\right]\right) \beta_{N S}\right\} \\
& +\left\{\left(E\left[X \mid D_{S}=1\right]-E\left[X \mid D_{S}=0\right]\right)\left(\beta_{S}-\beta_{N S}\right)\right\} \\
& =\Delta_{\beta}^{\mu}+\Delta_{X}^{\mu}+\Delta_{I}^{\mu}
\end{aligned}
$$

The first term in braces, denoted by $\Delta_{\beta}^{\mu}$, is the component due to slum-nonslum differences in the regression parameters of the factors, the second term in braces, denoted by $\Delta_{X}^{\mu}$, is the component due to slum-nonslum differences in the expected levels of the factors, and the third term in braces, denoted by $\Delta_{I}^{\mu}$, is the component due to the interaction between $\Delta_{\beta}^{\mu}$ and $\Delta_{X}^{\mu}$. Equation (3) can be computed by using sample means for the factors $\bar{X}_{g}$, and parameter estimates $\hat{\beta}_{g}$.

\section{Detailed decomposition}

We are also interested in analyzing the contributions of (groups of) individual factors to the aggregate decomposition components. The aggregate decomposition components are essentially sums of the corresponding decomposition components of the individual factors. We recognize that the detailed decompositions of $\Delta_{\beta}^{\mu}$ and $\Delta_{I}^{\mu}$ are not independent of the choice of the omitted 
categories for categorical factors in the regressions. That is, if the omitted category for a given categorical factor changes, the detailed decomposition results can change (Jones 1983; Oaxaca and Ransom 1999). While methods are available, we elect not to address this problem, in order to allow for the interpretability and comparability of our results (Fortin et al., 2011).

We also estimate all regressions and decompositions for stunting (a dichotomous variable) linearly based on ordinary least squares (limited probability model) and nonlinearly based on a binomial logit model. We estimate conditional fixed-effects binomial logit regressions for the specification with neighborhood-area fixed effects to avoid incidental parameters which can bias our estimations. Aggregate and detailed decompositions are based on binomial logit regressions, and the detailed decomposition results are obtained using the nonlinear decomposition approach proposed by Yun (2004).

In general, the results for mean HAZ versus the likelihood of stunting are similar. ${ }^{3}$ The robustness of the results to the choice of outcome indicator is likely because the sample around mean HAZ is not that far apart from the sample around the threshold HAZ for stunting.

\section{RESULTS}

\section{Mean nutrition outcomes}

Table 1 reports mean HAZ and stunting rates. In the pooled sample, mean HAZ was -1.69 SD below the international reference median, the moderate-to-severe stunting rate was $42 \%$, and the severe stunting rate was $20 \% .{ }^{4}$ Slum children have significantly worse mean nutrition status than

\footnotetext{
${ }^{3}$ The results for stunting are available upon request.

${ }^{4} \mathrm{~A}$ child is considered to be moderately-to-severely (severely) stunted if his or her height-for-age z-score is more than two (three) SD below the international reference population median.
} 
nonslum children. Relative to nonslum children, slum children have a mean HAZ that is lower by $0.58 \mathrm{SD}$, a moderate-to-stunting rate that is lower by $16 \mathrm{pp}$., and a severe stunting rate that is lower by 10 pp. $^{5}$

Comparing our statistics for city corporations to published statistics from the 2014 DHS for all rural and all urban areas, we note three main findings. ${ }^{6}$ First, mean child nutrition status for city corporations is poorer than that for all urban areas. For example, the moderate-to-severe stunting rate in the pooled city-corporation sample is $42 \%$, compared to $31 \%$ for all urban areas. Second, slum children in city corporations have poorer mean nutrition status than rural children. For example, the moderate-to-severe stunting rate for slum children is $48 \%$, compared to $38 \%$ for rural children. Third, nonslum children in city corporations have a lower moderate-to-severe stunting rate than rural children (31\% versus 38\%), but have a comparable severe stunting rate to children in all urban areas (31\%). The estimates suggest that mean child nutrition status for urban areas conceals substantial variation in child nutrition status across and within urban entities, and that mean nutrition status is especially poor for slum children not just as an urban subpopulation but as a national subpopulation.

\section{Effects of demographic and socioeconomic factors on child HAZ}

Table 2 reports the effects of a base set of child, maternal, household, and neighborhood-area factors on child HAZ. Table S1 in the online supplemental material provides definitions of these

\footnotetext{
${ }^{5}$ Our estimated stunting rates are a few percentage points off from those provided in the 2013 BUHS report (NIPORT et al., 2015), which we suspect is due to the loss of 100-200 children from our sample identified to have invalid anthropometric measurements.

${ }^{6}$ The DHS is representative for all urban areas and all rural areas, within each administrative division.
} 
and other factors that are examined subsequently. In the first set of regressions (columns 1-3), we include fixed effects for administrative divisions, identifying effects of child, maternal, household, and neighborhood-area factors based on variation within an administrative division. In the second set of regressions (columns 4-6), we include fixed effects for neighborhood areas, identifying effects of child, mother, and household factors based on variation within an area. Given that the share of children that experienced a recent illness with ARI symptoms is small, we construct a single indicator for whether the child experienced a recent illness with fever or ARI symptoms.

In terms of significant results from the regressions with administrative-division fixed effects, we find that child's age has a negative effect in all samples (pooled, slum, and nonslum). Child illness with fever or ARI symptoms has a negative effect of -0.14 SD in the nonslum sample. In the pooled sample, giving birth when the mother was younger than 18 years of age has a significant negative effect of $-0.22 \mathrm{SD}$, relative to giving birth when the mother was aged between 18 and 34. The pooled-sample effect is driven by the slum-sample effect.

Mother's regular exposure to mass media has a significant positive effect of 0.25 SD in the nonslum sample. Mother’s membership in an NGO has a significant positive effect of 0.17 SD in the slum sample. The effect of NGO membership on HAZ that we find may be mediated by the use of RMNCH services, which we do not control for in these regressions.

In all samples, mother's education attainment and household wealth have significant positive effects on HAZ. In the pooled sample, an additional year of mother's education has a positive effect of $0.03 \mathrm{SD}$, and a one SD increase in household wealth (that is, going from the mean to the $84^{\text {th }}$ percentile in the wealth index) has a positive effect of 0.22 SD. Household size 
has a negative effect in the slum and nonslum samples, but only the pooled-sample effect of $0.02 \mathrm{SD}$ is significant.

The availability of CHWs and NGO and public health facilities in the neighborhood area have negative, but mostly insignificant, effects on HAZ. The exception is the nonslum-sample effect of the availability of public health facilities, which is a significant -0.19 SD. The negative effects are presumably placement effects: areas served by CHWs, and NGO and public health facilities, may be socioeconomically disadvantaged in ways not adequately captured by household wealth and neighborhood environmental quality factors that we include in the regressions. The availability of private health facilities in the neighborhood area has a significant positive effect of 0.09 SD in the pooled sample, driven by the slum-sample effect (0.13 SD). Residing in a nonslum neighborhood area has a significant positive effect of 0.20 SD. Factors that have insignificant effects include the child's gender, the mother's employment status, and the availability of formal garbage collection and a proper sewerage system in the neighborhood area.

The results largely hold in the regressions with neighborhood-area fixed effects. Child's age, child illness, mother's age at child's birth, mother's education attainment, mother's membership in an NGO, and household wealth continue to have significant effects on HAZ. For factors that are similar between our analysis and that of Ahsan et al. (2017), inference results from our regressions with administrative-division fixed effects for slum and nonslum samples match those from their final stunting regression specifications. Our findings are also largely consistent with those from studies of the determinants of child undernutrition in selected slum settlements in various urban centers in Bangladesh (Alam et al., 2011; Fakir \& Khan, 2015; 
Zaman et al., 2015), as well as with international evidence on the determinants of child undernutrition in slum areas (Abuya, Ciera, \& Kimani-Murage, 2012; Goudet et al., 2017).

Effects of the use of MCH services on child HAZ

We examine the effects of antenatal care, delivery, and newborn exam at health facilities on HAZ. The information on antenatal care, delivery, and newborn exam were gathered in the 2013 BUHS only for the youngest child born in the three years before the survey (61\% of our full analysis sample).

The type of health facility for antenatal care or delivery may influence child nutrition status, if, for example, it is associated with quality of care. Mothers may choose to obtain antenatal care or deliver at a specific type of health facility because they expect to obtain better care there for any pregnancy or delivery complications. Even if they obtain better care, complications may induce a negative association between a higher-quality health facility or provider type and child nutrition status.

Table 3 reports the effects on HAZ of the use of MCH services at a facility (Panel A), and at a facility by type (Panel B). The regressions control for the base set of factors. Of note, the regressions control for household wealth, which could influence whether households use free or subsidized public or NGO health services, or fee-based private health services, as well as the availability of RMNCH services in the neighborhood area, offered through CHWs or health facilities.

Antenatal care at a health facility has a significant positive effect of 0.21 SD in the pooled sample. The effects are similar in size and significant in the slum and nonslum samples. 
Although positive, the effects of delivery or newborn exam at a health facility are insignificant in all samples.

Looking by type of health facility, antenatal care has a significant positive effect irrespective of the type in the pooled sample. The pooled-sample effect of $0.28 \mathrm{SD}$ for antenatal care in a public health facility is driven by the nonslum-sample effect (0.42 SD), whereas the pooled-sample effect of $0.14 \mathrm{SD}$ for antenatal care in an NGO health facility is driven by the slum-sample effect (0.18 SD). Delivery or newborn exam in a public health facility have significant positive effects in the pooled sample; the corresponding effects are not always significant in the slum and nonslum samples. The effects for delivery or newborn exam in other types of health facilities are insignificant in all samples.

\section{Effects of potential health-protective household amenities on child HAZ}

A sanitary community and home environment can protect children from illness, and thereby promote nutrition status. Reviews of international evidence suggest that poor water and sanitation facilities, and hygiene practices (WASH) are significantly associated with diarrhea and intestinal parasitic infection (Fewtrell et al., 2005; Clasen et al., 2007; Ziegelbauer et al., 2012; Strunz et al., 2014), and that diarrhea is significantly associated with poorer nutrition status (Dewey \& Mayers, 2011). The international evaluative evidence also generally suggests that improved WASH has a positive, albeit modest, effect on child nutrition status (Dangour et al., 2013). While much more limited, evidence from other countries suggest a negative link between indoor air pollution and nutrition status (Mishra \& Retherford, 2007), and a positive link between built home flooring and health and nutrition status (Cattaneo et al., 2009). 
In terms of evidence for Bangladesh, Luby \& Halder (2008) find that a handwashing place at the dwelling is significantly associated with a lower rate of ARI symptoms among young children in a sample of households in Dhaka city. Lin et al. (2013) find that sanitary household WASH conditions are significantly associated with a lower rate of intestinal parasitic infection, better nutrition status, and lower rates of markers of environmental enteropathy among young children in a sample of rural households. Baker et al. (2016) find that young children in households that share toilet facilities have a significantly higher rate of diarrhea in Mirzapur city (as well as in selected urban centers in Africa and other South Asian countries).

Motivated by this evidence, we examine the effects of household access to piped drinking water and an improved toilet, safe disposal of garbage by the household, household use of a clean fuel for cooking, a finished floor in the dwelling, and a handwashing site with soap and water at the dwelling.

Table 4 reports the effects of potential health-protective household amenities on HAZ. Given that virtually all households had access to improved toilets, we restrict the analysis to children in such households, and examine the effect of shared access to an improved toilet. The amenities are strongly correlated with our household wealth index even when they are excluded from the construction of the index. Thus, we examine the effects of the amenities, controlling for the base set of factors, but excluding the household wealth index.

Sharing access to an improved toilet with nine or more households has a significant negative effect of $-0.20 \mathrm{SD}$ in the pooled sample. The pooled-sample effect is driven by the slum-sample effect $(-0.27 \mathrm{SD})$. Sharing access to an improved toilet with fewer households also has negative effects in all samples but they are insignificant. The presence of a handwashing site with soap and water has a significant positive effect of 0.24 SD for nonslum children. The 
corresponding effect for slum children is $0.04 \mathrm{SD}$, and insignificant. All other amenities have insignificant effects. Ahsan et al. (2017) also examine safe garbage disposal and access to improved toilets, and find that these factors have insignificant effects on child stunting status in their full slum and nonslum regression specifications.

As a caveat, our analysis of the effects of household amenities does not account for the quality, reliability, or time availability of these amenities. For example, our finding that households that share toilets with several other households have lower child HAZ may be because these communal toilets are particularly unclean and poorly maintained, as documented by Alam et al. (2016). Such conditions make open defecation more likely, and increase the risk of disease transmission.

Decomposition of the slum-nonslum difference in mean child HAZ

Table 5 reports the decomposition results for the slum-nonslum difference in mean child HAZ (the outcome gap), which is a significant -0.59 SD, into (1) slum-nonslum differences in the estimated mean levels of factors (the factor-level gap), (2) slum-nonslum differences in the estimated effects of the factors (the effect gap), and (3) interactions between factor-level and effect gaps (the interaction gap), at the aggregate and detailed (individual factor) decomposition levels. For the detailed decomposition, we only report results for factors that are significant. We do not convert the decomposition results into proportions of the outcome gap due to factor level, effect, and interaction gaps as some studies do because this exercise fails to account for the imprecision in the estimates. The aggregate and detailed decompositions are performed for the base set of factors. 
To simplify the results and facilitate interpretation, we grouped together selected individual factors for the detailed decomposition. Specifically, we grouped (1) indicators for mother's age at time of child's birth into a “mother's age at child's birth” group; (2) indicators for formal garbage collection and proper sewerage system into a "neighborhood area environmental health” group; (3) indicators for the availability of CHWs and of public, NGO, and private health facilities into an "RMNCH service availability" group; and (4) indicators for administrative divisions into a "division” group.

At the aggregate decomposition level, while both the overall factor-level gap and the overall effect gap are significant contributors to the outcome gap, the contribution of the overall factor-level gap is larger in size (-0.38 SD versus $-0.19 \mathrm{SD})$. The overall interaction gap also contributes to the outcome gap, but its contribution is small (-0.01 SD) and insignificant.

At the detailed decomposition level, the main significant factor-level gap is for household wealth (-0.28 SD), followed by the factor-level gap for mother's education attainment (-0.09 SD). The only significant contributor to the overall effect gap (that is, in the same direction as the overall effect gap) is the mother's age at child's birth. In addition, the only significant contributor to the overall interaction gap is the mother's age at child's birth. The decomposition results remain unchanged when we include factors for the use of MCH services in the regressions.

\section{Decomposition of the change in mean HAZ for slum and nonslum children}

We also decompose the change in mean HAZ from 2006 to 2013 for slum and nonslum children in the relevant city corporations. Over the period from 2006 to 2013, mean HAZ significantly increased for slum and nonslum children. Specifically, mean HAZ increased 
by $0.23 \mathrm{SD}$ for slum children, and by $0.20 \mathrm{SD}$ for nonslum children. Moderate-to-severe and severe stunting rates significantly declined for slum children by -8 pp. and -5 pp., respectively. Stunting rates for nonslum children also declined, but the magnitudes were insignificant.

Table 6 reports the decomposition results for the change in mean HAZ (the outcome change) into (1) changes in the estimated mean levels of factors (the factor-level change), (2) changes in the estimated effects of the factors (the effect change), and (3) interactions between factor-level and effect changes (the interaction change). We do this separately for slum and nonslum children. We do not decompose the change in the slum-nonslum difference in mean HAZ because the difference changed little over the period.

For slum children, at the aggregate decomposition level, the factor-level change significantly contributed $0.09 \mathrm{SD}$ to the outcome change. The effect and interaction changes contributed $0.05 \mathrm{SD}$ and $0.07 \mathrm{SD}$, respectively, to the outcome change, but the contributions are insignificant. At the detailed decomposition level, the significant contributors to the overall factor-level change are mother's education attainment (0.04 SD) and household wealth (0.06 SD). The only significant contributor to the overall effect and interaction changes is the child's birth order (0.24 SD and 0.05 SD, respectively).

The results for nonslum children are mostly similar. At the aggregate decomposition level, only the factor-level change significantly contributed 0.13 SD to the outcome change. At the detailed decomposition level, the significant contributors to the overall factor-level change are child's recent illness with fever or ARI symptoms (0.02 SD), mother's education attainment (0.04 SD), and household wealth (0.09 SD). There were no significant contributors to the overall effect change, and the only significant contributor to the overall interaction change is the neighborhood area's RMNCH service availability (0.16 SD). The evidence generally suggests 
that the changes in mean HAZ for slum and nonslum children were driven by changes in the mean levels of factors, mainly by the increases in the mean levels of mother's education attainment and household wealth. The decomposition results remain qualitatively similar when we include factors for the use of $\mathrm{MCH}$ services in the regressions.

\section{CONCLUSION}

In terms of the main results, we find that mean child nutrition status is substantially poorer for slum than nonslum residents. Comparisons with 2014 DHS statistics that are representative for urban and rural areas indicate that the mean nutrition status of slum children is poorer than for rural children. However, the mean nutrition status of nonslum children is the same as for children in all urban areas, which indicates a cause for concern for city-corporation children in general and slum children in particular.

Child's age, mother's age at child's birth, mother's education attainment, and household wealth have significant effects on HAZ, which are robust to the inclusion of neighborhood-area fixed effects in the regressions. The positive effect on HAZ from residing in a nonslum neighborhood area remains significant even after controlling for a range of factors. Access to improved toilets that are shared with a large number of other households has a negative effect on HAZ for slum children, whereas a handwashing site with soap and water at the dwelling has a positive effect on HAZ for nonslum children. All the above results are based on the 2013 BUHS.

With respect to the decomposition results, we find that the difference in mean HAZ between slum and nonslum children in 2013 is driven by differences in the mean levels of factors for slum and nonslum children, in particular, mother's education attainment and household wealth. Similarly, the increase in mean HAZ between 2006 and 2013 for both slum and nonslum 
children in the relevant city corporations is driven by increases in the mean levels of factors, in particular, mother's education attainment and household wealth. These findings are consistent with those from studies for Bangladesh that empirically examine the factors associated with the increase in mean child nutrition status (Headey et al., 2015; Headey, Hoddinott, \& Park, 2016; Nguyen et al., 2017), or the factors associated with the rural-urban difference in mean child nutrition status (Srinivasan, Zanello, \& Shankar, 2013).

Our analysis has at least three important limitations, which can affect the reliability of our findings. First, we are not able to account for the endogeneity in the household decision to reside in a slum versus a nonslum area, or for the endogeneity of household decisions regarding say the use of potential health-protective household amenities or MCH services (which may be interrelated with the decision on where to reside). Second, the regressions and decompositions would fail to point out factors that may matter for child nutrition status but exhibit limited variability across households and children, small differences in means between slum and nonslum areas, or changed little on average in our data. Third, our results may be affected by omitted variable bias. The 2013 BUHS did not collect information on potentially relevant factors such as: for the child, birth weight, diarrhea and treatment, immunization, and deworming; for the mother, physical and mental health (for example, underweight status) and decisionmaking authority over household expenditures on own and child health, and over food for the household; and, for the household, food security. The absence of paternal factors in our analysis may also be source of omitted variable bias.

Consequently, the policy conclusions we draw are necessarily circumspect. Policies, programs, and partnerships that aim to produce gains in household economic status and female formal education attainment are consistent with our results, as are initiatives to enhance the 
health and nutrition payoffs of the use of MCH services and community and home environmental health infrastructure for the urban poor in general and slum residents in particular. 


\section{REFERENCES}

Abuya, Benta A., James Ciera, and Elizabeth Kimani-Murage. 2012. "Effect of Mother's Education on Child's Nutritional Status in the Slums of Nairobi." BMC Pediatrics, 12(80).

Adams, Alayne M., Herfina Y. Nababan, and S. M. Manzoor Ahmed Hanifi. 2015. "Building Social Networks for Maternal and Newborn Health in Poor Urban Settlements: A Cross Sectional Study in Bangladesh.” PLoS ONE, 10(4): e0123817.

Adams, Alayne M., Rubana Islam, and Tanvir Ahmed. 2015. "Who Serves the Urban Poor? A Geospatial and Descriptive Analysis of Health Services in Slum Settlements in Dhaka, Bangladesh.” Health Policy and Planning, 30: i32-i45.

Afsana, Kaosar, and Syed Shabab Wahid. 2013. "Health Care for Poor People in the Urban Slums of Bangladesh.” Lancet, 382: 2049-2051.

Ahsan, Karar Zunaid, Shams El Arifeen, Md. Abdullah Al-Mamun, Shusmita H. Khan, and Nitai Chakraborty. 2017. "Effects of Individual, Household and Community Characteristics on Child Nutritional Status in the Slums of Urban Bangladesh.” Archives of Public Health, 75(9).

Alam, Mahbub-Ul, Farzana Yeasmin, Farzana Begum, Mahbubur Rahman, Fosiul Alam Nisame, Stephen Luby, Peter Winch, and Leanne Unicomb. 2016. "Can Behavior Change Approaches Improve the Cleanliness and Functionality of Shared Toilets? A Randomized Control Trial in Dhaka, Bangladesh.” Discussion Paper 9. Water and Sanitation for the Urban Poor.

Alam, Md. Ariful, M. A. Hakim, M. A. Rouf, Md. Obidul Haque, M. E. Ali, and I. S. M. Ziadul. 2011. "Nutritional Status of Urban Slum Children Below Five Years: Assessment by Anthropometric Measurements with Special Reference to Socioeconomic Status.” Journal of Food, Agriculture, and Environment, 9(2): 85-90.

Alam, Narul, Dilruba Begum, Syed Masud Ahmed, and Peter Kim Streatfield. 2011. "MANOSHI Community Health Solutions in Bangladesh: Impact Evaluation Surveys in Dhaka Urban Slums 2007, 2009, 2011.” Scientific Report 118. Dhaka: International Center for Diarrhoeal Diseases Research.

Angeles, Gustavo, Peter Lance, Janine Barden-O’Fallon, Nazrul Islam, A. Q. M. Mahbub, and Nurul Islam Nazem. 2009. "The 2005 Census and Mapping of Slums in Bangladesh: Design, Select Results and Application.” International Journal of Health Geographics, 8(32).

Arifeen, Shams El., Aliki Christou, Laura Reichenbach, Ferdous Arifina Osman, Kishwar Azad, Khaled Shamsul Islam, Faruque Ahmed, Henry B. Perry, and David H. Peters. 2013. "Community-Based Approaches and Partnerships: Innovations in Health-Service Delivery in Bangladesh.” Lancet, 382(9909): 2012-2026.

Baker, Kelly K., Ciara E. O’Reilly, Myron M. Levine, Karen L. Kotloff, James P. Nataro, Tracy L. Ayers, et al. 2016. "Sanitation and Hygiene-Specific Risk Factors for Moderate-toSevere Diarrhea in Young Children in the Global Enteric Multicenter Study, 2007-2011: Case-Control Study.” PLoS Med, 13(5): e1002010.

Banu, Morsheda, and Hashima E. Nasreen. 2011. "Factors Influencing the Performance of Delivery Centers in Urban Slums in Bangladesh: A Qualitative Study.” OIDA International Journal of Sustainable Development, 2(12): 67-76.

Black, Robert E., Cesar G. Victora, Susan P. Walker, Zulfiqar A. Bhutta, Parul Christian, Mercedes de Onis, Majid Ezzati, Sally Grantham-McGregor, Joanne Katz, Reynaldo 
Martorell, Ricardo Uauy, and the Maternal and Child Nutrition Study Group. 2013. "Maternal and Child Undernutrition and Overweight in Low-Income and Middle-Income Countries." Lancet, 382: 427-451.

Black, Robert E., Lindsay H. Allen, Zulfiqar A. Bhutta, Laura. E. Caulfield, Mercedes de Onis, Majid Ezzati, Colin Mathers, Juan Rivera. 2008. "Maternal and Child Undernutrition: Global and Regional Exposures and Health Consequences.” Lancet, 371(9608): 243-260.

Blinder, Alan S. 1973. "Wage Discrimination: Reduced Form and Structural Estimates." Journal of Human Resources, 8(4): 436-455.

Cattaneo, Matias D., Sebastian Galiani, Paul J. Gertler, Sebastian Martinez, and Rocio Titiunik. 2009. "Housing, Health, and Happiness." American Economic Journal: Economic Policy, 1(1): 75-105.

Cesar, Victora G., Linda Adair, Caroline Fall, Pedro C. Hallal, Reynaldo Martorell, Linda Richter, and Harshpal Singh Sachdev. 2008. "Maternal and Child Undernutrition: Consequences for Adult Health and Human Capital." Lancet, 371(9609): 340-357.

Clasen, Thomas, Wolf-Peter Schmidt, Tamer Rabie, Ian Roberts, and Sandy Cairncross. 2007. "Interventions to Improve Water Quality for Preventing Diarrhoea: Systematic Review and Meta-Analysis.” British Medical Journal, 334(782).

Currie, Janet, and Tom Vogl. 2013. "Early-Life Health and Adult Circumstance in Developing Countries.” Annual Review of Economics, 5: 1-36.

Dangour, A. D., L. Watson, O. Cumming, S. Boisson, Y. Che, Y. Velleman, S. Cavill, E. Allen, and R. Uauy. 2013. "Interventions to Improve Water Quality and Supply, Sanitation and Hygiene Practices, and their Effects on the Nutritional Status of Children." Cochrane Database of Systematic Reviews, 8.

Daymont, Thomas N., and Paul J. Andrisani. 1984. "Job Preferences, College Major, and the Gender Gap in Earnings.” Journal of Human Resources, 19(3): 408-428.

Dewey, Kathryn G., and Daniel R. Mayers. 2011. "Early Child Growth: How Do Nutrition and Infection Interact? Maternal \& Child Nutrition, 7(Suppl. 3): 129-142.

El Arifeen, Shams, Aliki Christou, Laura Reichenbach, Ferdous Arfina Osman, Kishwar Azad, Khaled Shamsul Islam, Faruque Ahmed, Henry B. Perry, David H. Peters. 2013. "Community-Based Approaches and Partnerships: Innovations in Health-Service Delivery in Bangladesh” Lancet, 382: 2012-2026.

Ezeh, Alex, Oyinlola Oyebode, David Satterthwaite, Yen-Fu Chen, Robert Ndugwa, Jo Sartori, Blessing Mberu, G. J. Melendez-Torres, Tilahun Haregu, Samuel I. Watson, Waleska Caiaffa, Anthony Capon, and Richard J. Lilford. 2017. "The History, Geography, and Sociology of Slums and the Health Problems of People Who Live in Slums." Lancet, 389(10068): 547-558.

Fakir, Adnan M. S., and M. Wasiqur Rahman Khan. 2015. "Determinants of Malnutrition Among Urban Slum Children in Bangladesh.” Health Economics Review, 5(22).

Fewtrell, Lorna, Rachel B. Kaufmann, David Kay, Wayne Enanoria, Laurence Haller, and John M Colford Jr. 2005. "Water, Sanitation, and Hygiene Interventions to Reduce Diarrhoea in Less Developed Countries: A Systematic Review and Meta-Analysis." Lancet Infectious Diseases, 5: 42-52.

Fortin, Nicole, Thomas Lemiuex, and Sergio Firpo. 2011. "Decomposition Methods in Economics" Chapter 1. Pages 1-102. Edited by Orley Ashenfelter and David Card. In Handbook of Labor Economics Volume 4a. Elsevier B.V. 
Gazi, Rukhsana, Marufa Sultana, Humayun Kabir, and Nirod Chandra Saha. 2015. “Accessibility, Availability and Perceived Quality of Reproductive Health Services in Selected Urban Areas of Bangladesh: User and Nonusers' Perspectives.” Reproductive System and Sexual Disorders, 4(3).

GOB (Government of Bangladesh). 2014. Population and Housing Census 2011: National Volume 3: Urban Area Report. Dhaka: Bangladesh Bureau of Statistics, Statistics Division, Ministry of Planning, GOB.

GOB (Government of Bangladesh). 2015. Preliminary Report on the Census of Slum Areas and Floating Population 2014.Dhaka: Bangladesh Bureau of Statistics, Statistics and Informatics Division, Ministry of Planning, GOB.

Goudet, Sophie, Paula Griffiths, Barry Bogin, and Nyovani Madise. 2017. "Interventions to Tackle Malnutrition and Its Risk Factors in Children Living in Slums: A Scoping Review.” Annals of Human Biology, 44(1): 1-10.

Haddad, Slim, Katia Sarla Mohindra, Kendra Siekmans, Genevieve Mak, and Delampady Narayana. 2012. “'Health Divide’ Between Indigenous and Non-Indigenous Populations in Kerala, India: Population Based Study.” BMC Public Health, 12: 390.

Headey, Derek, John Hoddinott, and Seollee Park. 2016. "Drivers of Nutritional Change in Four South Asian Countries: A Dynamic Observational Analysis.” Maternal \& Child Nutrition, 12(Suppl. 1): 210-218.

Headey, Derek, John Hoddinott, Disha Ali, Roman Tesfaye, and Mekdim Dereje. 2015. "The Other Asian Enigma: Explaining the Rapid Reduction of Undernutrition in Bangladesh.” World Development, 66: 749-761.

Heller, Lauren R. 2013. "Do Slums Matter? Location and Early Childhood Preventive Care Choices among Urban Residents of Bangladesh.” Social Science and Medicine, 94: 43-55.

Hossain, M. A., M. Moniruzzaman, and M. A. Islam. 2010. "Urban Environmental Health in Bangladesh Slum: A Comparative Study of Two Metropolitan Cities. Journal of Science Foundation, 8: 67-76.

ICDDRB (International Center for Diarrheal Disease Research, Bangladesh). 2015. Technical Assistance for Assessment of Contribution of Ministry of Health and Family Welfare for Urban Health Services. Dhaka: ICDDRB.

IFPRI (International Food Policy Research Institute). 2016. Global Nutrition Report 2016: From Promise to Impact: Ending Malnutrition by 2030. Washington, DC: IFPRI.

Islam, Md. Rezaul, Md. Farukuzzaman, and Md. Amirul Islam. 2014. "Situation of Slum's Children in Dhaka City, Bangladesh: A Sample Survey." Journal of Economics and Sustainable Development, 5(18): 27-33.

Jones, F. L. 1983. “On Decomposing the Wage Gap: A Critical Component of Blinder’s Method.” Journal of Human Resources, 18(1): 126-130.

Kamal, Nahid, Sian Curtis, Mohammad S. Hasan, and Kanta Jamil. 2016. "Trends in Equity in Use of Maternal Health Services in Urban and Rural Bangladesh.” International Journal for Equity in Health, 15: 27.

Khatun, Fatema, Sabrina Rasheed, Allisyn C. Moran, Ashraful M. Alam, Mohammad Sohel Shomik, Munira Sultana, Nuzhat Choudhury, Mohammad Iqbal, and Abbas Bhuiya. 2012. "Causes of Neonatal and Maternal Deaths in Dhaka Slums: Implications for Service Delivery.” BMC Public Health, 12(1): 84.

Kumar, Abhishek, and Aditya Singh. 2013. "Decomposing the Gap in Childhood Undernutrition between Poor and Non-Poor in Urban India, 2005-06.” PLoS ONE, 8(5): e64972. 
Lance, Peter, Gustavo Angeles, and Nahid Kamal. 2012. Smiling Sun Franchise Program (BSSFP) Impact Evaluation Report. Chapel Hill, NC: MEASURE Evaluation.

Lilford, Richard J., Oyinlola Oyebode, David Satterthwaite, G. J. Melendez-Torres, Yen-Fu Chen, Blessing Mberu, Samuel I. Watson, Jo Sartori, Robert Ndugwa, Waleska Caiaffa, Tilahun Haregu, Anthony Capon, Ruhi Saith, and Alex Ezeh. 2017. "Improving the Health and Welfare of People Who Live in Slums.” Lancet, 389(10068): 559-570.

Lin, Audrie, Benjamin F. Arnold, Sadia Afreen, Rie Goto, Tarique Mohammad Nurul Huda, Rashidul Haque, et al. 2013. "Household Environmental Conditions are Associated with Enteropathy and Impaired Growth in Rural Bangladesh.” American Journal of Tropical Medicine \& Hygiene, 89(1): 130-137.

Luby, Stephen P., and Amal K. Halder. 2008. “Associations among Handwashing Indicators, Wealth, and Symptoms of Childhood Respiratory Illness in Urban Bangladesh.” Tropical Medicine and International Health, 13(6): 835-844.

Mberu, Blessing U., Tilahun N. Haregu, Catherine Kyobutungi, and Alex C. Ezeh. 2016. "Health and Health-Related Indicators in Slum, Rural, and Urban Communities: A Comparative Analysis” Global Health Action, 9: 33163.

Mishra, Vinod, and Robert D. Retherford. 2007. "Does Biofuel Smoke Contribute to Anemia and Stunting in Early Childhood.” International Journal of Epidemiology, 36: 117-129.

Nahar, Samsun, and M. Maksudur Rahman. 2013. "Factors Influencing Health and Healthcare Delivery System for the Urban Poor in Chittagong City, Bangladesh.” Asian Journal of Management Research, 4(2): 288-296.

Nguyen, Phuong Hong, Derek Headey, Edward A. Frongillo, Lan Mai Tran, Rahul Rawat, Marie T. Ruel, and Purnima Menon. 2017. “Changes in Underlying Determinants Explain Rapid Increases in Child Linear Growth in Alive \& Thrive Study Areas Between 2010 and 2014 in Bangladesh and Vietnam.” Journal of Nutrition, 147(3): 462-469.

NIPORT (National Institute of Population Research and Training), MEASURE Evaluation, International Centre for Diarrheal Disease Research, Bangladesh (ICDDR, B), and Associates for Community and Population Research (ACPR). 2008. 2006 Bangladesh Urban Health Survey. Dhaka, Bangladesh and Chapel Hill, North Carolina, USA: NIPORT, MEASURE Evaluation, ICDDR, B, and ACPR.

NIPORT (National Institute of Population Research and Training), International Centre for Diarrhoeal Disease Research, Bangladesh (ICDDRB), and MEASURE Evaluation. 2015. Bangladesh Urban Health Survey 2013 Final Report. Dhaka, Bangladesh and Chapel Hill, North Carolina: NIPORT, ICDDRB, and MEASURE Evaluation.

NIPORT (National Institute of Population Research and Training)-Bangladesh, Mitra and Associates, and ICF International. 2016. Bangladesh Demographic and Health Survey 2014. Dhaka: NIPORT, Mitra and Associates, and ICF International.

Oaxaca, Ronald L., and Michael R. Ransom. 1999. "Identification in Detailed Wage Decompositions.” Review of Economic and Statistics, 81(1): 154-157.

Oaxaca, Ronald. 1973. "Male-Female Wage Differentials in Urban Labor Markets.” International Economic Review, 14(3): 693-709.

Srinivasan, Chittur S., Giacomo Zanello, and Bhavani Shankar. 2013 "Rural-Urban Disparities in Child Nutrition in Bangladesh and Nepal.” BMC Public Health, 13: 581.

Strunz, Eric C., David G. Addiss, Meredith E. Stocks, Stephanie Ogden, Jurg Utzinger, and Matthew C. Freeman. 2014. "Water, Sanitation, Hygiene, and Soil-Transmitted Helminth Infection: A Systematic Review and Meta-Analysis.” PLoS Med, 11(3): e1001620. 
Sudhinaraset, May, Matthew Ingram, Heather K. Lofthouse, and Dominic Montagu. 2013. "What is the Role of Informal Healthcare Providers in Developing Countries? A Systematic Review." PLoS ONE, 8(2): e54978.

UN (United Nations). 2015. Transforming Our World: The 2030 Agenda for Sustainable Development. New York: UN.

UN-Habitat (United Nations Human Settlements Programme) 2016. World Cities Report 2016: Urbanization and Development: Emerging Futures. Nairobi: Kenya: UN-Habitat.

UN-Habitat (United Nations Human Settlements Programme). 2003. The Challenge of Slums: Global Report on Human Settlements 2003. London: Earthscan Publications.

UNICEF (United Nations Children's Fund). 1998. The State of the World's Children. New York: UNICEF.

Wagstaff, Adam, and Eddy van Doorslaer, and Naoko Watanabe. 2003. "On Decomposing the Causes of Health Sector Inequalities with an Application to Malnutrition Inequalities in Vietnam." Journal of Econometrics, 112: 207-223.

World Bank. 2016. World Development Indicators 2016. Washington, DC: World Bank.

Yun, Myeong-Su. 2004. "Decomposing Differences in the First Moment." Economic Letters, 82(2): 275-280.

Zaman, Sultan Uz, Nuhad Raisa Seoty, Masud Alam, Rashidul Haque, and Nawzia Yasmin. 2015 "Household Food Insufficiency and Child Nutritional Status in Urban Slum, Dhaka, Bangladesh.” Acta Medica International, 2(1): 65-69.

Ziegelbauer, Kathrin, Benjamin Speich, Daniel Mausezahl, Robert Bos, Jennifer Keiser, Jurg Utzinger. 2012. "Effect of Sanitation on Soil-Transmitted Helminth Infection: Systematic Review and Meta-Analysis.” PLoS Med, 9(1): e1001162. 
Table 1. Mean HAZ and stunting rates

\begin{tabular}{|c|c|c|c|c|c|c|}
\hline & \multicolumn{4}{|c|}{ City corporations, 2013} & \multicolumn{2}{|c|}{ Bangladesh, 2014} \\
\hline & Pooled & Slum & Nonslum & $\begin{array}{c}\text { Slum- } \\
\text { nonslum }\end{array}$ & All rural & All urban \\
\hline & (1) & (2) & (3) & (4) & (5) & (6) \\
\hline HAZ & -1.69 & -1.88 & -1.30 & $-0.58 * * *$ & -1.60 & -1.30 \\
\hline Moderate-to-severe stunting & 0.42 & 0.48 & 0.31 & $0.16 * * *$ & 0.38 & 0.31 \\
\hline Severe stunting & 0.20 & 0.23 & 0.13 & $0.10 * * *$ & 0.12 & 0.10 \\
\hline
\end{tabular}

Note: The sample comprises of children aged 0-59 months. Statistics are estimated using data the 2013 Bangladesh Urban Health Survey and the 2014 Demographic and Health Survey (DHS). Estimates are adjusted for sampling weights. Inference is based on robust standard errors, clustered at the neighborhood-area level. $* * *$ denotes $\mathrm{p}<0.01$, ${ }^{* *} \mathrm{p}<0.05$, and $* \mathrm{p}<0.1$. 
Table 2. Effects on child HAZ, base set of factors, 2013

Ordinary least squares regressions

\begin{tabular}{|c|c|c|c|c|c|c|}
\hline \multirow[t]{2}{*}{ Factor } & \multicolumn{3}{|c|}{ Administrative-division fixed effects } & \multicolumn{3}{|c|}{ Neighborhood-area fixed effects } \\
\hline & $\begin{array}{l}\text { Pooled } \\
\text { (1) }\end{array}$ & $\begin{array}{c}\text { Slum } \\
(2)\end{array}$ & $\begin{array}{c}\text { Nonslum } \\
\text { (3) }\end{array}$ & $\begin{array}{l}\text { Pooled } \\
\text { (4) }\end{array}$ & $\begin{array}{c}\text { Slum } \\
\text { (5) }\end{array}$ & $\begin{array}{c}\text { Nonslum } \\
\text { (6) }\end{array}$ \\
\hline \multicolumn{7}{|l|}{ Child } \\
\hline \multirow{7}{*}{ Recently ill with fever or ARI symptoms } & $\begin{array}{c}-0.016 * * * \\
(0.002)\end{array}$ & $\begin{array}{c}-0.017 * * * \\
(0.002)\end{array}$ & $\begin{array}{c}-0.013 * * * \\
(0.002)\end{array}$ & $\begin{array}{c}-0.016 * * * \\
(0.002)\end{array}$ & $\begin{array}{c}-0.017 * * * \\
(0.002)\end{array}$ & $\begin{array}{c}-0.014 * * * \\
(0.003)\end{array}$ \\
\hline & 0.041 & 0.040 & 0.014 & 0.052 & 0.068 & -0.002 \\
\hline & $(0.045)$ & $(0.059)$ & $(0.068)$ & $(0.053)$ & $(0.063)$ & $(0.096)$ \\
\hline & 0.031 & 0.046 & 0.006 & 0.017 & 0.022 & -0.006 \\
\hline & $(0.024)$ & $(0.030)$ & $(0.038)$ & $(0.029)$ & $(0.035)$ & $(0.052)$ \\
\hline & -0.020 & 0.030 & $-0.139 *$ & -0.055 & -0.013 & $-0.171^{*}$ \\
\hline & $(0.052)$ & $(0.069)$ & $(0.071)$ & $(0.063)$ & $(0.075)$ & $(0.103)$ \\
\hline \multicolumn{7}{|l|}{ Mother } \\
\hline \multirow[t]{2}{*}{ Age at child's birth $<18$} & $-0.219 * * *$ & $-0.290 * * *$ & 0.037 & $-0.263^{* *}$ & $-0.344 * * *$ & 0.117 \\
\hline & $(0.085)$ & $(0.104)$ & $(0.133)$ & $(0.105)$ & $(0.117)$ & $(0.197)$ \\
\hline \multirow[t]{2}{*}{ Age at child's birth >34 } & 0.085 & -0.146 & $0.525^{* *}$ & -0.001 & -0.114 & 0.337 \\
\hline & $(0.134)$ & $(0.165)$ & $(0.210)$ & $(0.153)$ & $(0.178)$ & $(0.279)$ \\
\hline \multirow[t]{2}{*}{ Completed education (in years) } & $0.033 * * *$ & $0.038 * * *$ & $0.022 *$ & $0.033 * * *$ & $0.032^{* *}$ & $0.033^{*}$ \\
\hline & $(0.008)$ & $(0.012)$ & $(0.012)$ & $(0.011)$ & $(0.013)$ & $(0.018)$ \\
\hline \multirow[t]{2}{*}{ Employed } & -0.06 & -0.041 & -0.08 & -0.047 & -0.046 & -0.053 \\
\hline & $(0.062)$ & $(0.075)$ & $(0.101)$ & $(0.074)$ & $(0.082)$ & $(0.155)$ \\
\hline \multirow[t]{2}{*}{ Regularly exposed to mass media } & 0.105 & 0.069 & $0.246^{*}$ & 0.078 & 0.051 & 0.258 \\
\hline & $(0.066)$ & $(0.076)$ & $(0.136)$ & $(0.085)$ & $(0.091)$ & $(0.214)$ \\
\hline \multirow[t]{2}{*}{ Member of an NGO } & 0.079 & $0.171^{* *}$ & -0.195 & 0.101 & $0.152 *$ & -0.077 \\
\hline & $(0.072)$ & $(0.083)$ & $(0.122)$ & $(0.081)$ & $(0.088)$ & $(0.182)$ \\
\hline \multicolumn{7}{|l|}{ Household } \\
\hline \multirow{2}{*}{ Standardized wealth index } & $0.219 * * *$ & $0.212 * * *$ & $0.248 * * *$ & $0.205^{* * *}$ & $0.179 * * *$ & $0.248 * *$ \\
\hline & $(0.038)$ & $(0.047)$ & $(0.064)$ & $(0.053)$ & $(0.064)$ & $(0.098)$ \\
\hline \multirow[t]{2}{*}{ Number of members } & $-0.022 *$ & -0.018 & -0.030 & -0.017 & -0.012 & -0.030 \\
\hline & $(0.013)$ & $(0.017)$ & $(0.019)$ & $(0.017)$ & $(0.020)$ & $(0.031)$ \\
\hline \multicolumn{7}{|l|}{ Neighborhood area } \\
\hline \multirow{2}{*}{ Formal garbage collection available } & -0.018 & -0.006 & -0.083 & - & - & - \\
\hline & $(0.069)$ & $(0.083)$ & $(0.119)$ & & & \\
\hline \multirow[t]{2}{*}{ Proper sewerage system available } & 0.037 & 0.020 & 0.058 & - & - & - \\
\hline & $(0.056)$ & $(0.076)$ & $(0.079)$ & & & \\
\hline \multirow[t]{2}{*}{ CHW service available } & -0.018 & -0.017 & -0.052 & - & - & - \\
\hline & $(0.055)$ & $(0.072)$ & $(0.080)$ & & & \\
\hline \multirow[t]{2}{*}{ NGO health facility available } & -0.013 & -0.069 & 0.089 & - & - & - \\
\hline & $(0.059)$ & $(0.075)$ & $(0.079)$ & & & \\
\hline \multirow[t]{2}{*}{ Public health facility available } & -0.077 & -0.009 & $-0.186 *$ & - & - & - \\
\hline & $(0.079)$ & $(0.103)$ & $(0.110)$ & & & \\
\hline \multirow[t]{2}{*}{ Private health facility available } & $0.089 *$ & $0.131^{*}$ & 0.048 & - & - & - \\
\hline & $(0.053)$ & $(0.070)$ & $(0.077)$ & & & \\
\hline Nonslum area & $\begin{array}{c}0.197 * * * \\
(0.062)\end{array}$ & - & - & - & - & - \\
\hline \multirow[t]{2}{*}{ Intercept } & $-1.576^{* * *}$ & $-1.567 * * *$ & $-1.365^{* * *}$ & $-1.357 * * *$ & $-1.434 * * *$ & $-1.340 * * *$ \\
\hline & $(0.153)$ & $(0.190)$ & $(0.252)$ & $(0.153)$ & $(0.170)$ & (0.349) \\
\hline Observations & 7,565 & 5,000 & 2,565 & 7,565 & 5,000 & 2,565 \\
\hline$R$-squared statistic & 0.082 & 0.064 & 0.064 & 0.268 & 0.171 & 0.409 \\
\hline
\end{tabular}

Note: ARI = acute respiratory infection; CHW = community health worker. The sample comprises of children aged 0-59 months. Statistics are estimated using the 2013 Bangladesh Urban Health Survey. Estimates are adjusted for sampling weights. Robust standard errors, clustered at the neighborhood-area level, are reported in parentheses. ${ }^{* * *}$ denotes $p<0.01,{ }^{* *} p<0.05$, and $* p<0.1$. 
Table 3. Effects of type of health facility/provider for antenatal care, delivery, and newborn exam on child HAZ, 2013, youngest child born in the three years before the survey Ordinary least squares regressions

\begin{tabular}{|c|c|c|c|}
\hline & $\begin{array}{l}\text { Pooled } \\
\text { (1) }\end{array}$ & $\begin{array}{c}\text { Slum } \\
\text { (2) }\end{array}$ & $\begin{array}{c}\text { Nonslum } \\
\text { (3) }\end{array}$ \\
\hline & \multicolumn{3}{|c|}{ A. Use of health facility } \\
\hline \multirow[t]{6}{*}{ Antenatal care at a health facility } & $\begin{array}{c}0.210 * * \\
(0.079)\end{array}$ & $\begin{array}{c}0.198 * * \\
(0.094)\end{array}$ & $\begin{array}{c}0.213^{*} \\
(0.123)\end{array}$ \\
\hline & 0.088 & 0.079 & 0.082 \\
\hline & $(0.071)$ & $(0.090)$ & $(0.112)$ \\
\hline & 0.059 & 0.072 & 0.036 \\
\hline & $(0.076)$ & $(0.099)$ & $(0.107)$ \\
\hline & \multicolumn{3}{|c|}{ B. Use of health facility type } \\
\hline \multicolumn{4}{|l|}{ Antenatal care } \\
\hline Public health facility & $\begin{array}{c}0.281 * * \\
(0.116)\end{array}$ & $\begin{array}{c}0.176 \\
(0.148)\end{array}$ & $\begin{array}{c}0.417 * * \\
(0.162)\end{array}$ \\
\hline NGO health facility & $0.143^{*}$ & $0.182 *$ & 0.001 \\
\hline & $(0.089)$ & $(0.105)$ & $(0.141)$ \\
\hline Private health facility & $0.214^{* *}$ & 0.200 & $0.243^{*}$ \\
\hline & $(0.092)$ & $(0.117)$ & $(0.137)$ \\
\hline \multicolumn{4}{|l|}{ Delivery } \\
\hline Public health facility & $0.223 * *$ & 0.195 & 0.230 \\
\hline & $(0.100)$ & $(0.135)$ & $(0.147)$ \\
\hline NGO health facility & 0.007 & 0.034 & -0.121 \\
\hline & $(0.093)$ & $(0.112)$ & $(0.154)$ \\
\hline Private health facility & 0.052 & 0.020 & 0.074 \\
\hline & $(0.098)$ & $(0.153)$ & $(0.127)$ \\
\hline \multicolumn{4}{|l|}{ Newborn exam } \\
\hline Public health facility & $0.264^{*}$ & $0.284 *$ & 0.233 \\
\hline & $(0.108)$ & $(0.147)$ & $(0.155)$ \\
\hline NGO health facility & -0.067 & -0.057 & -0.102 \\
\hline & $(0.112)$ & $(0.135)$ & $(0.164)$ \\
\hline Private health facility & 0.009 & 0.033 & -0.024 \\
\hline & $(0.101)$ & (0.157) & $(0.128)$ \\
\hline
\end{tabular}

Note: Regressions control for the base set of factors (see table 3). Statistics are estimated using the 2013 Bangladesh Urban Health Survey. Estimates are adjusted for sampling weights. Robust standard errors, clustered at the neighborhood-area level, are reported in parentheses. ${ }^{* * *}$ denotes $p<0.01$, ${ }^{* *} p<0.05$, and $* p<0.1$. 
Table 4. Effects of health-protective household amenities on child HAZ, 2013 Ordinary least squares regressions

\begin{tabular}{|c|c|c|c|}
\hline & $\begin{array}{c}\text { Pooled } \\
(1)\end{array}$ & $\begin{array}{l}\text { Slum } \\
(2)\end{array}$ & $\begin{array}{c}\text { Nonslum } \\
\text { (3) }\end{array}$ \\
\hline Unshared access to piped drinking water & $\begin{array}{c}0.119 \\
(0.108)\end{array}$ & $\begin{array}{l}-0.015 \\
(0.170)\end{array}$ & $\begin{array}{c}0.102 \\
(0.146)\end{array}$ \\
\hline Shared access to piped drinking water & $\begin{array}{c}0.066 \\
(0.064)\end{array}$ & $\begin{array}{c}0.098 \\
(0.076)\end{array}$ & $\begin{array}{l}-0.045 \\
(0.116)\end{array}$ \\
\hline Access to an improved toilet, shared with $<9$ other $\mathrm{HH}$ & $\begin{array}{l}-0.101 \\
(0.093)\end{array}$ & $\begin{array}{l}-0.129 \\
(0.130)\end{array}$ & $\begin{array}{l}-0.033 \\
(0.128)\end{array}$ \\
\hline Access to an improved toilet, shared with $\geq 9$ other $\mathrm{HH}$ & $\begin{array}{c}-0.202 * \\
(0.103)\end{array}$ & $\begin{array}{c}-0.268^{* *} \\
(0.133)\end{array}$ & $\begin{array}{c}0.026 \\
(0.174)\end{array}$ \\
\hline Safe disposal of garbage & $\begin{array}{c}0.081 \\
(0.062)\end{array}$ & $\begin{array}{c}0.076 \\
(0.078)\end{array}$ & $\begin{array}{c}0.115 \\
(0.093)\end{array}$ \\
\hline Use of a clean cooking fuel & $\begin{array}{l}-0.006 \\
(0.080)\end{array}$ & $\begin{array}{r}-0.046 \\
(0.091)\end{array}$ & $\begin{array}{c}0.191 \\
(0.168)\end{array}$ \\
\hline Finished floor in dwelling & $\begin{array}{c}0.079 \\
(0.078)\end{array}$ & $\begin{array}{c}0.113 \\
(0.086)\end{array}$ & $\begin{array}{c}0.043 \\
(0.187)\end{array}$ \\
\hline Handwashing site, with water and soap, at dwelling & $\begin{array}{c}0.093 \\
(0.061) \\
\end{array}$ & $\begin{array}{c}0.038 \\
(0.076) \\
\end{array}$ & $\begin{array}{c}0.237 * * \\
(0.095) \\
\end{array}$ \\
\hline
\end{tabular}

Note: $\mathrm{HH}=$ households. Sample is restricted to children aged 0-59 months in households with access to an improved toilet. Regressions control for the base set of factors (see table 3), except for household asset index. Statistics are estimated using the 2013 Bangladesh Urban Health Survey. Estimates are adjusted for sampling weights. Robust standard errors, clustered at the neighborhood-area level, are reported in parentheses. ${ }^{* * *}$ denotes $p<0.01, * * p<0.05$, and $* p<0.1$. 
Table 5. Decomposition of slum-nonslum difference in mean child HAZ, 2013 Based on ordinary least squares regressions

\begin{tabular}{|c|c|c|c|c|}
\hline Factors & $\begin{array}{l}\text { Outcome } \\
\text { (1) }\end{array}$ & $\begin{array}{c}\text { Factor level } \\
\text { (2) }\end{array}$ & $\begin{array}{l}\text { Effect } \\
\text { (3) }\end{array}$ & $\begin{array}{c}\text { Interaction } \\
\text { (4) }\end{array}$ \\
\hline & \multicolumn{4}{|c|}{ Aggregate } \\
\hline & $\begin{array}{c}-0.581^{* * *} \\
(0.053)\end{array}$ & $\begin{array}{c}-0.379 * * * \\
(0.054)\end{array}$ & $\begin{array}{c}-0.193^{* *} \\
(0.075)\end{array}$ & $\begin{array}{l}-0.010 \\
(0.075)\end{array}$ \\
\hline & \multicolumn{4}{|c|}{ Detailed } \\
\hline Child ill with fever or ARI symptoms & & $\begin{array}{c}-0.007^{*} \\
(0.004)\end{array}$ & $\begin{array}{c}0.047 * * \\
(0.028)\end{array}$ & $\begin{array}{l}0.008^{*} \\
(0.006)\end{array}$ \\
\hline Mother: completed education & & $\begin{array}{c}-0.091^{* *} \\
(0.047)\end{array}$ & - & - \\
\hline Mother: age at child birth & & - & $\begin{array}{c}-0.053^{* * *} \\
(0.017)\end{array}$ & $\begin{array}{c}-0.017 * \\
(0.009)\end{array}$ \\
\hline Standardized wealth index & & $\begin{array}{c}-0.280 * * * \\
(0.066)\end{array}$ & - & - \\
\hline
\end{tabular}

Note: ARI = acute respiratory infection. The sample comprises of children aged 0-59 months. Statistics are estimated using the 2013 Bangladesh Urban Health Survey. Estimates are adjusted for sampling weights. Robust standard errors, clustered at the neighborhood-area level, are reported in parentheses. ${ }^{* * *}$ denotes $p<0.01 ;{ }^{* *} p<0.05$ and ${ }^{*} p<0.1$. 
Table 6. Decomposition of change in mean child HAZ between 2006 and 2013 Based on ordinary least squares regressions

\begin{tabular}{|c|c|c|c|c|}
\hline & $\begin{array}{c}\text { Outcome } \\
\text { (1) }\end{array}$ & $\begin{array}{c}\text { Factor level } \\
\text { (2) }\end{array}$ & $\begin{array}{l}\text { Effect } \\
(3)\end{array}$ & $\begin{array}{c}\text { Interaction } \\
(4)\end{array}$ \\
\hline & \multicolumn{4}{|c|}{ A. Slum areas } \\
\hline & \multicolumn{4}{|c|}{ Aggregate } \\
\hline & $\begin{array}{c}0.222^{* * * *} \\
(0.069)\end{array}$ & $\begin{array}{c}0.094 * * \\
(0.044)\end{array}$ & $\begin{array}{c}0.054 \\
(0.088)\end{array}$ & $\begin{array}{c}0.074 \\
(0.069)\end{array}$ \\
\hline & \multicolumn{4}{|c|}{ Detailed } \\
\hline Child: birth order & & $\begin{array}{c}-0.023^{*} \\
(0.013)\end{array}$ & $\begin{array}{c}0.239 * * \\
(0.119)\end{array}$ & $\begin{array}{l}0.045^{*} \\
(0.024)\end{array}$ \\
\hline Mother: completed education & & $\begin{array}{c}0.043 * * * \\
(0.015)\end{array}$ & - & - \\
\hline \multirow[t]{4}{*}{ Household: standardized wealth index } & & $\begin{array}{c}0.055^{* * *} \\
(0.019)\end{array}$ & - & - \\
\hline & \multicolumn{4}{|c|}{ B. Nonslum areas } \\
\hline & \multicolumn{4}{|c|}{ Aggregate } \\
\hline & $\begin{array}{c}0.210 * * \\
(0.101)\end{array}$ & $\begin{array}{c}0.134 * * \\
(0.054)\end{array}$ & $\begin{array}{c}0.019 \\
(0.120)\end{array}$ & $\begin{array}{c}0.057 \\
(0.106)\end{array}$ \\
\hline & \multicolumn{4}{|c|}{ Detailed } \\
\hline Child: Recent illness with ARI or fever & & $\begin{array}{l}0.024^{*} \\
(0.013)\end{array}$ & - & - \\
\hline Mother: completed education & & $\begin{array}{l}0.036^{*} \\
(0.020)\end{array}$ & - & - \\
\hline Household: standardized wealth index & & $\begin{array}{c}0.093 * * * \\
(0.030)\end{array}$ & - & - \\
\hline Neighborhood area: RMNCH service availability & & - & - & $\begin{array}{c}0.164 * * \\
(0.072)\end{array}$ \\
\hline
\end{tabular}

Note: ARI = acute respiratory infection; RMNCH = reproductive, maternal, neonatal, and child health. "RMNCH service availability" groups together indicators for the availability of community health workers, and NGO, public, and private health facilities. The sample comprises of children aged 0-59 months. Statistics are estimated using the 2006 and 2013 Bangladesh Urban Health Surveys. Estimates are adjusted for sampling weights. Robust standard errors, clustered at the neighborhood-area level, are reported in parentheses. ${ }^{* * *}$ denotes $p<0.01$, ** $p<0.05$, and $* p<0.1$. 